\title{
The CFD-Based Simulation of a Horizontal Axis Micro Water Turbine
}

\section{Werayoot LAHAMORNCHAIYAKUL}

\author{
Department of Mechanical Engineering, Rajamangala University of Technology Lanna Phitsanulok \\ Campus, Phitsanulok 65000, Thailand
}

(Corresponding author's e-mail: werayootrmutl@gmail.com)

Received: 14 December 2019, Revised: 7 April 2020, Accepted: 10 May 2020

\begin{abstract}
A horizontal axis micro water turbine generator has been designed for use as a source of power generation where the reservoir construction has only a low head. It uses the natural flow rate of water to generate a specific power output. The power is, however, limited by the flow rate of water which has to be sufficient to keep operating a suitable number of revolutions per minute for the blades. Tis research aimed to introduce a new blade can be disassembled and modular on the wheel blade and developing for optimum design of the horizontal axis micro water turbine generator. A 3D model of the wheel blade in the horizontal axis micro water turbine generator was created by using Autodesk Inventor Professional 2018 software. Computational Fluid Dynamics (CFD) analysis and structural Finite Element Analysis (FEA) are presented in this paper. CFD analysis was performed to obtain the velocity and pressure difference between the concave and convex regions of the wheel blade while FEA was used to obtain the structural response of the wheel blade due to the water velocity load applied in terms of stresses and displacements.
\end{abstract}

Keywords: Computational Fluid Dynamics (CFD), Finite Element Analysis (FEA), Micro water turbine generator, Stress analysis

\section{Introduction}

Water energy generation is one of the key factors for economic and social development in both the developed and developing nations of the world. Water energy is clean energy; when used in small hydro power units, it is renewable energy that has large potential and low cost of installation [1]. A water turbine generator is a machine that extracts energy from a water flow. Regular water turbines, such as wind turbines and water turbine wheels, are optimally designed for electricity production [2]. A micro water turbine is a mechanical device that extracts energy from a fluid flow of water and converts it into useful work [3]. They require only a low head of water to operate. In this study, CFD was used as a tool for the design and analysis of fluid dynamics. The CFD is one example of a finite element method that has become a powerful tool for determining numerical solutions and for the analysis of fluid machinery problems in developing an optimum design for a water turbine generator. Finite element analysis (FEA) is defined as dividing a complex problem into smaller and simpler problems that can be solved by using existing knowledge of the mechanics of materials in conjunction with appropriate mathematical tools [4]. Finite element analysis involves dividing the model into small pieces in a process called meshing. The behavior of each element can be defined under all possible support and load scenarios derived in order. This also deals with the failure analysis of a wheel blade and the design can be checked and then, proper solutions derived to improve the effectiveness of the turbine. The new design is be simulated using the commercial software and the stress analysis module in Autodesk Inventor Professional software. This work investigates the effect that loading approximation has on deflection, stress distribution results and 
http://wjst.wu.ac.th

we can design of water turbine blade that can be disassembling and modular on a wheel blade shown in Figure 1a. And results of the CFD and FEA simulation will be presented in this paper.

\section{Numerical simulation model}

\section{CFD model}

Turbulence simulation is to predict the physical behavior of turbulent flow generated in a system using numerical methods. In the fluid regions, commercial software solves the Navier-Stokes's equations, which are the formulation of mass, momentum, and energy conservation laws [5].

$$
\begin{aligned}
& \frac{\partial \rho}{\partial t}+\frac{\partial\left(\rho u_{i}\right)}{\partial x_{i}}=0 \\
& \frac{\partial\left(\rho u_{i}\right)}{\partial t}+\frac{\partial}{\partial x_{j}}\left(\rho u_{i} u_{j}\right)+\frac{\partial P}{\partial x_{i}}=\frac{\partial}{\partial x_{j}}\left(\tau_{i j}+\tau_{i j}^{R}\right)+S_{i} \\
& \frac{\partial \rho H}{\partial t}+\frac{\partial \rho u_{i} H}{\partial x_{i}}=\frac{\partial}{\partial x_{i}}\left(u_{j}\left(\tau_{i j}+\tau_{i j}^{R}\right)+q_{i}\right)+\frac{\partial p}{\partial t}-\tau_{i j}^{R} \frac{\partial u_{i}}{\partial x_{j}}+\rho \varepsilon+S_{i} u_{i}+Q_{H} \\
& H=h+\frac{u^{2}}{2}
\end{aligned}
$$

Commercial software employs transport equations for the turbulence kinetic energy and its dissipation rate, using the $k-\varepsilon$ model [5].

$$
\begin{aligned}
& \frac{\partial \rho k}{\partial t}+\frac{\partial \rho k u_{i}}{\partial x_{i}}=\frac{\partial}{\partial x_{i}}\left(\left(\mu+\frac{\mu_{t}}{\sigma_{k}}\right) \frac{\partial k}{\partial x_{i}}\right)+\tau_{i j}^{R} \frac{\partial u_{i}}{\partial x_{j}}-\rho \varepsilon+\mu_{t} P_{B}, \\
& \frac{\partial \rho \varepsilon}{\partial t}+\frac{\partial \rho \varepsilon u_{i}}{\partial x_{i}}=\frac{\partial}{\partial x_{i}}\left(\left(\mu+\frac{\mu_{t}}{\sigma_{\varepsilon}}\right) \frac{\partial \varepsilon}{\partial x_{i}}\right)+C_{\varepsilon 1} \frac{\varepsilon}{k}\left(f_{1} \tau_{i j}^{R} \frac{\partial u_{i}}{\partial x_{j}}+C_{B} \mu_{t} P_{B}\right)-f_{2} C_{\varepsilon 2} \frac{\rho \varepsilon^{2}}{k} \\
& \tau_{i j}=\mu S_{i j}, \tau_{i j}^{R}=\mu_{t} S_{i j}-\frac{2}{3} \rho k \delta_{i j}, S_{i j}=\frac{\partial u_{i}}{\partial x_{j}}+\frac{\partial u_{j}}{\partial x_{i}}-\frac{2}{3} \delta_{i j} \frac{\partial u_{k}}{\partial x_{k}}, \\
& P_{B}=-\frac{g_{i}}{\sigma_{B}} \frac{1}{\rho} \frac{\partial \rho}{\partial x_{i}},
\end{aligned}
$$

where $C_{\mu}=0.09, C_{\varepsilon 1}=1.44, C_{\varepsilon 2}=1.92, \sigma_{k}=1, \sigma_{\varepsilon}=1.3, \sigma_{B}=0.9, C_{B}=1$ if $P_{B}>0, C_{B}=0$

if $P_{B}<0$ the turbulent viscosity is determined from $\mu_{t}=f_{u} \cdot \frac{C_{\mu} \rho k^{2}}{\varepsilon}$

The standard $k-\varepsilon$ model combines reasonable accuracy, time economy, and robustness for a wide range of turbulent flows. To improve the predictive accuracy of $k-\varepsilon$ models, more transport equations have been derived.

FEA model

Processing requires no user interaction. All analysis types are based on classical engineering concepts. These concepts can be formulated into matrix equations that are suitable for analysis using FEM. It calculates transformation matrices. It maps element equations into the global system, and, hence, assembly of elements takes place. Boundary conditions are introduced and solution procedures are 
http://wjst.wu.ac.th

performed. For structural analysis problem the displacement, stiffness, and loads are related as given below:

$[K]\{q\}=\{F\}$

where $[\mathrm{K}]=$ structural stiffness.

$\{\mathrm{q}\}=$ Nodal displacement.

$[\mathrm{F}]=$ load matrix.

In the solution phase, we ended up with governing equations for each element. By solving these equations at each node, we obtained the degrees of freedom, which gave the approximate behavior of the complete model [6].

\section{Materials}

After performing a detailed problem study of the micro water turbine generator that had been used in the analysis, we formulated the properties that were required to be possessed for the water turbine design.

\section{Design of micro water turbine}

Data design

The following assumptions or considerations were made in the design process of the wheel blade of the micro water turbine using design guides and information from published literature:

- Head water setup $=3,4$ and $5 \mathrm{~m}$.

- Wheel blade diameter $(\mathrm{D})=80 \mathrm{~mm}$.

- Nozzle diameter $\left(\mathrm{N}_{\mathrm{d}}\right)=15 \mathrm{~mm}$.

\section{Concept design of wheel blade}

The design of the wheel blade depends on the analysis of a velocity diagram. The following are the notations used in the velocity diagram shown in Figure 1b.
$\mathrm{V}_{1}, \mathrm{~V}_{2}$
$=$ velocities at blade inlet and outlet
$\mathrm{Vr}_{1}, \mathrm{Vr}_{2}$
$=$ velocities of fluid at blade inlet and outlet
$\mathrm{Vw}_{1}, \mathrm{Vw}_{2}$
$=$ Tangential component of velocities at blade inlet and outlet
$\mathrm{u}_{1}=\mathrm{u}_{2}$
$=$ blade speed

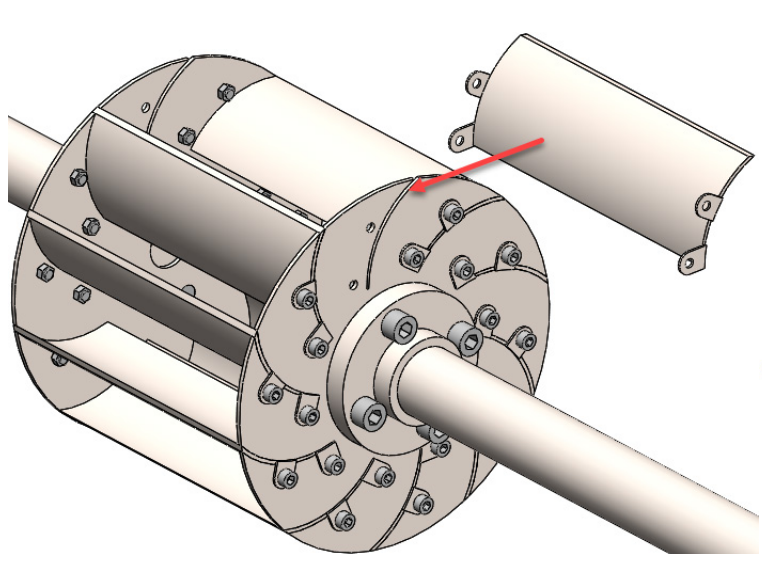

(a) The modular design of wheel blade

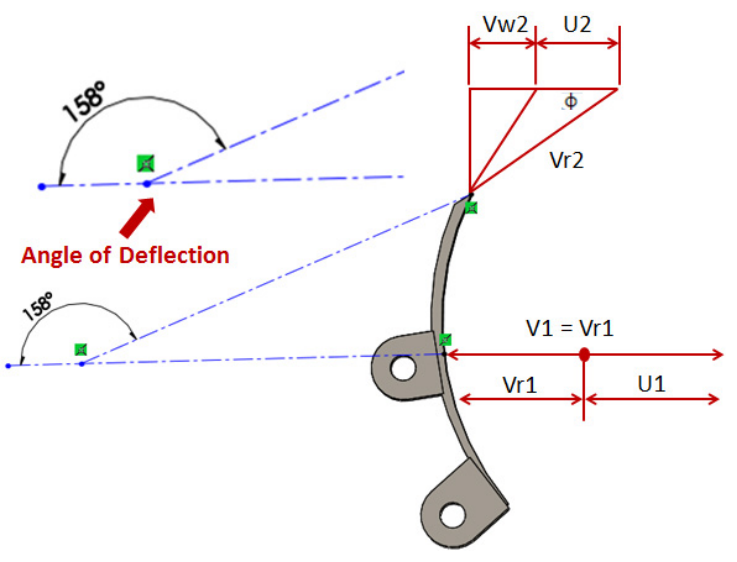

(b) Water velocity Diagram

Figure 1 Detail of wheel blade design. 
http://wjst.wu.ac.th

In this study, the following assumptions were made: water velocity is $\mathrm{V} 1=\sqrt{2 \times 9.81 \times 3}=7.76$ $\mathrm{m} / \mathrm{s}$. The entire component of velocity $\mathrm{V}_{1}$ is along a tangential direction. Hence $\mathrm{Vw}_{1}=\mathrm{V}_{1}=7.76 \mathrm{~m} / \mathrm{s}$

For maximum efficiency of the water turbine, blade speed (u) should be as close as possible to half the velocity of the water jet. However, $u=0.5 \mathrm{~V}_{1}$ is not realistic. In a realistic design of a water turbine, the assumptions for blade speed are taken as $0.44-0.46$ the velocity of the jet $[3,7]$.

$\mathrm{u}=0.45 \times 7.76=3.492 \mathrm{~m} / \mathrm{s}$.

Relative velocity, $\mathrm{Vr}_{1}$ is determined from the velocity diagram as;

$\mathrm{Vr}_{1}=\mathrm{V}_{1}-\mathrm{u}=7.76 \mathrm{~m} / \mathrm{s}-3.492 \mathrm{~m} / \mathrm{s}=4.268 \mathrm{~m} / \mathrm{s}$

As compared to relative velocity at the inlet.

$\mathrm{Vr}_{2}=0.85 \mathrm{Vr}_{1}=0.85-4.268 \mathrm{~m} / \mathrm{s}=3.63 \mathrm{~m} / \mathrm{s}$

Angle, $\varphi$, in outlet, the triangle is calculated as, $180^{\circ}-158^{\circ}=22^{\circ}$

The tangential velocity of the fluid at the outlet is calculated from the velocity triangle as follows,

$$
\begin{aligned}
\mathrm{Vw}_{2} & =\mathrm{Vr}_{2}\left(\operatorname{Cos} 22^{\circ}\right)-\mathrm{u} \\
& =3.63 \mathrm{~m} / \mathrm{s} \times\left(\operatorname{Cos} 22^{\circ}\right)-3.492 \mathrm{~m} / \mathrm{s}=-0.127 \mathrm{~m} / \mathrm{s}
\end{aligned}
$$

Calculation of power transferred $(\mathrm{Pt})$ as follows,

$$
\begin{aligned}
\mathrm{Pt} & =\rho A V_{1}\left(V w_{1}+V w_{2}\right) x u \\
& =1,000 \mathrm{~kg} / \mathrm{m}^{3} \times 1.77 \times 10^{-4} \mathrm{~m}^{2} \times 7.76 \mathrm{~m} / \mathrm{s} \times(7.76 \mathrm{~m} / \mathrm{s}+(-0.127 \mathrm{~m} / \mathrm{s})) \times 3.492 \mathrm{~m} / \mathrm{s} \\
& =36.61 \mathrm{~W}
\end{aligned}
$$

Calculation of kinetic energy (Ke) as follows,

$$
\begin{aligned}
\mathrm{Ke} & =\frac{1}{2} \times\left(\rho A V_{1}\right) \times V_{1}^{2} \\
& =0.5 \times\left(1,000 \mathrm{~kg} / \mathrm{m}^{3} \times 1.77 \times 10^{-4} \mathrm{~m}^{2} \times 7.76 \mathrm{~m} / \mathrm{s}\right) \times(7.76 \mathrm{~m} / \mathrm{s})^{2} \\
& =41.34 \mathrm{~W}
\end{aligned}
$$

The efficiency of the micro water turbine is defined as the ratio of power transferred to the wheel blade by the water jet to the kinetic energy of the water jet per second.

$$
\text { Efficiency } \begin{aligned}
(\eta) & =\mathrm{Pt} / \mathrm{Ke} \\
& =36.61 \mathrm{~W} / 41.34 \mathrm{~W} \\
& =88 \%
\end{aligned}
$$

Calculation of the shaft speed of the micro water turbine as follows,

$$
\begin{aligned}
\mathrm{rpm} & =60 \times \mathrm{u} / 3.14 \times \mathrm{D}_{\text {Wheel blade }} \\
& =838 \mathrm{rpm}
\end{aligned}
$$

Force acting on the nozzle, Fz, is calculated:

$$
\begin{aligned}
\mathrm{Fz} & =\rho A V_{1}\left(V w_{1}+V w_{2}\right) \\
& =1,000 \mathrm{~kg} / \mathrm{m}^{3} \times 1.77 \times 10^{-4} \mathrm{~m}^{2} \times 7.76 \mathrm{~m} / \mathrm{s} \times(7.76 \mathrm{~m} / \mathrm{s}+(-0.127 \mathrm{~m} / \mathrm{s})) \\
& =10.48 \mathrm{~N}
\end{aligned}
$$




\author{
General procedure for CFD and FEA [8,9] \\ Process of CFD \\ Preprocessing \\ - Define the CAD domain of the problem for CFD analysis. \\ - Define the mesh element type. \\ - Define the material properties \\ - Define the geometric properties for CFD analysis. \\ - Define the boundary conditions and define the initial value of the analysis.
}

\title{
Solution
}

- Computed values are then used by back substitution to compute additional, derived variables, such as reaction velocity, pressure, and rotation.

\section{Post-processing}

- Postprocessor software contains sophisticated routines used for sorting, printing, and plotting selected results from a computational fluid dynamics solution.

\section{Process of FEA}

Preprocessing

- Define the geometric domain of the problem for FEA analysis.

- Define the mesh element type.

- Define the material properties.

- Define the geometric properties.

- Define the element connectivity (mesh the model).

- Define the physical constraints (boundary conditions).

- Define the loadings and fixed support.

\section{Solution}

- Computes the unknown values of the primary field variable(s).

- Computed values are then used by back substitution to compute additional, derived variables, such as reaction forces, element stresses, and heat flow.

\section{Post-processing}

- Postprocessor software contains sophisticated routines used for sorting, printing, and plotting selected results from a finite element solution.

Model and boundary condition of the micro water turbine wheel

The model, using CAD Design, as created in Autodesk Inventor Professional version 2018 software is shown in Figures 2a and $\mathbf{2 b}$. The CFD meshing of the geometry was performed using commercial software while and the FEA meshing of the geometry was performed in Stress Analysis as outlined above. The wheel has a blade size diameter of $80 \mathrm{~mm}$ and a shaft size diameter of $15 \mathrm{~mm}$ as seen in Figure 2a. 
Table 1 Specifications of the horizontal axis micro water turbine generator.

\begin{tabular}{lcc}
\hline \multicolumn{1}{c}{ List Data } & Value & Unit \\
\hline Axis of water turbine & Horizontal & - \\
Wheel blade diameter & 80 & $\mathrm{~mm}$ \\
Inlet diameter & 15 & $\mathrm{~mm}$ \\
No. of blades & 10 & - \\
Blade width & 72 & $\mathrm{~mm}$ \\
Shaft diameter & 15 & $\mathrm{~mm}$ \\
Range of head water & $3-5$ & $\mathrm{~m}$ \\
\hline
\end{tabular}

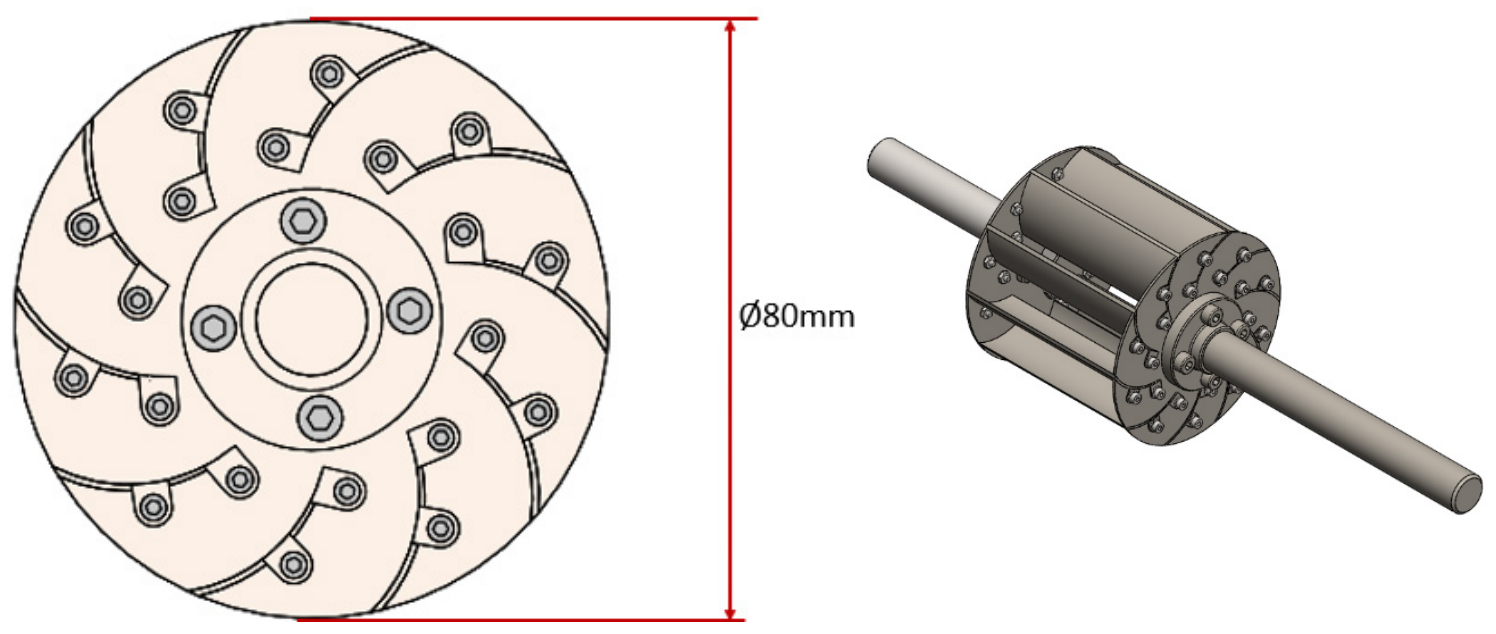

(a) Main wheel blade.

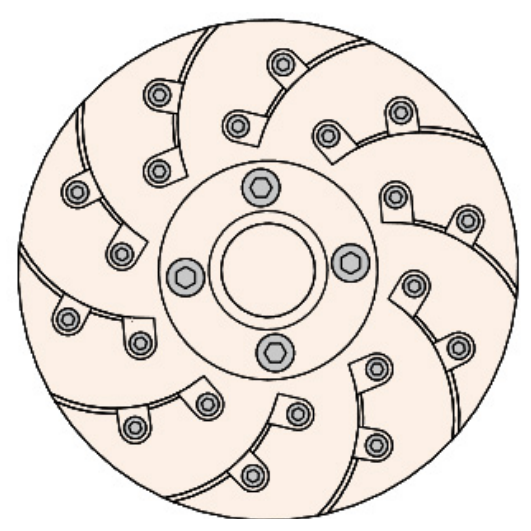

(b) Right angle view of the wheel blade.

Figure 2 Geometry of the micro water turbine wheel [13]. 
http://wjst.wu.ac.th

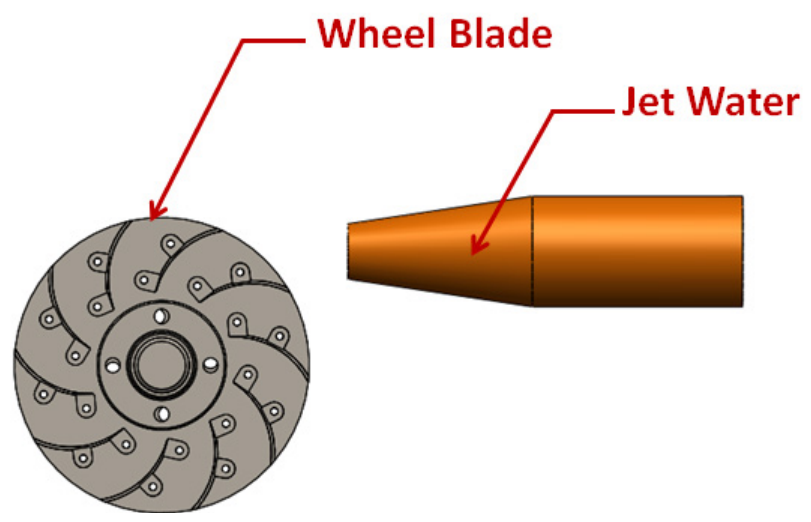

(a) Wheel blade and water jet system [13].

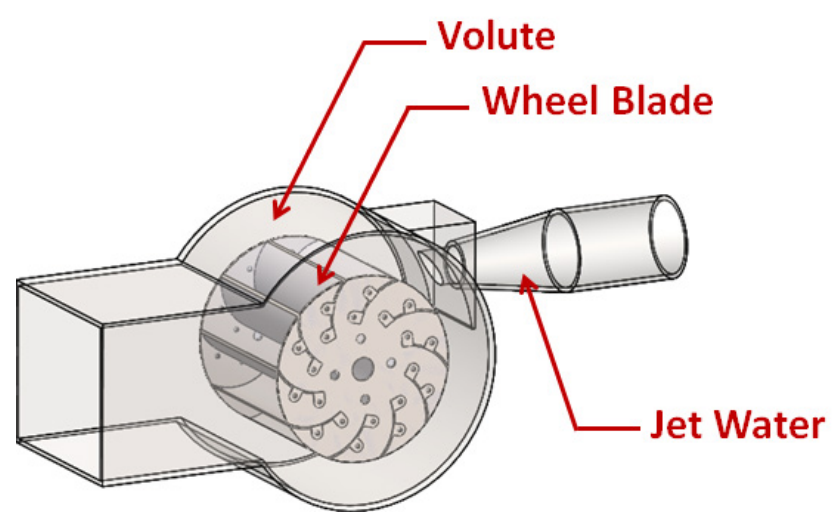

(b) Main water turbine analysis.

Figure 3 Geometry of wheel blade, volute, and water jet for analysis.

Figure 3a shows the wheel blade and water jet configured in this research for numerical simulation of the rotating region analysis. The main water turbine used for the analysis is shown in Figure 3b.

CFD meshing of the geometry is carried out in the fluid computation analysis in commercial software [10], details of which:

- Type of element: hexahedron.

- The total cell element of analysis is 2,603,012. Mesh results are shown in Figure 4. 

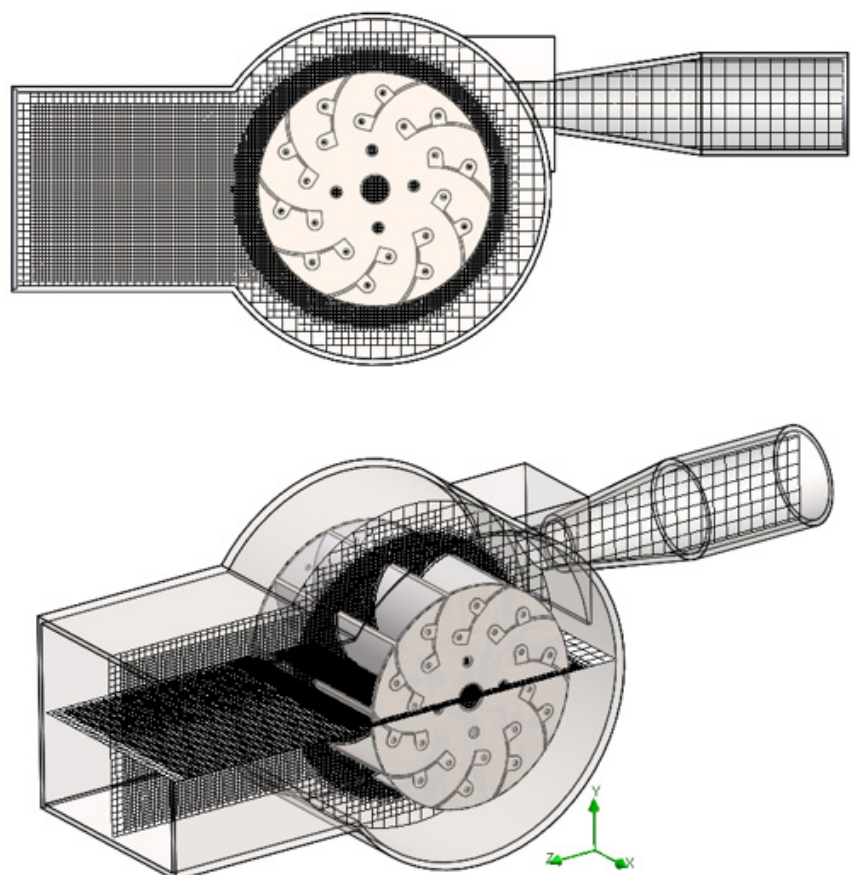

Figure 4 CFD meshing of the water turbine wheel geometry using Commercial software2018.

FEA meshing of the geometry is also done in the Stress Analysis Module of Autodesk Inventor Professional version 2018 software, details of which are:

- Type of element: triangular

- Elements: 38,457

- Nodes: 80,380

- Grading factor: 1.5

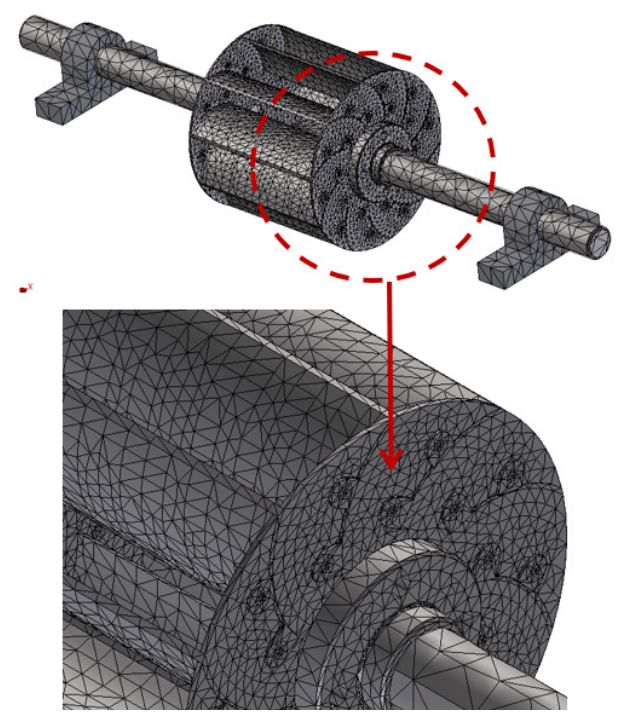

Figure 5 FEA meshing of the water turbine wheel geometry using Autodesk Inventor Professional 2018. 
http://wjst.wu.ac.th

Fluid boundary conditions for the analysis, namely the inlet water velocity range was $7.76,8.85$, and $9.90 \mathrm{~m} / \mathrm{s}$, and the outlet is at static pressure [10]. The defined gravity of force $-Z$ is $9.81 \mathrm{~m} / \mathrm{s}^{2}$ and defined boundary conditions of the rotational speed setup are 800, 1,100, and 1,400 rpm. Boundary conditions for the CFD analysis are shown in Table 2 and Figure 6.

Table 2 Wheel blade speeds from different water velocity conditions were calculated.

\begin{tabular}{ccc}
\hline Low head $(\mathbf{m})$ & Velocity $(\mathbf{m} / \mathbf{s})$ & Wheel blade speed $(\mathbf{r p m})$ \\
\hline 3 & 7.76 & 800 \\
4 & 8.85 & 1,100 \\
5 & 9.90 & 1,400 \\
\hline
\end{tabular}

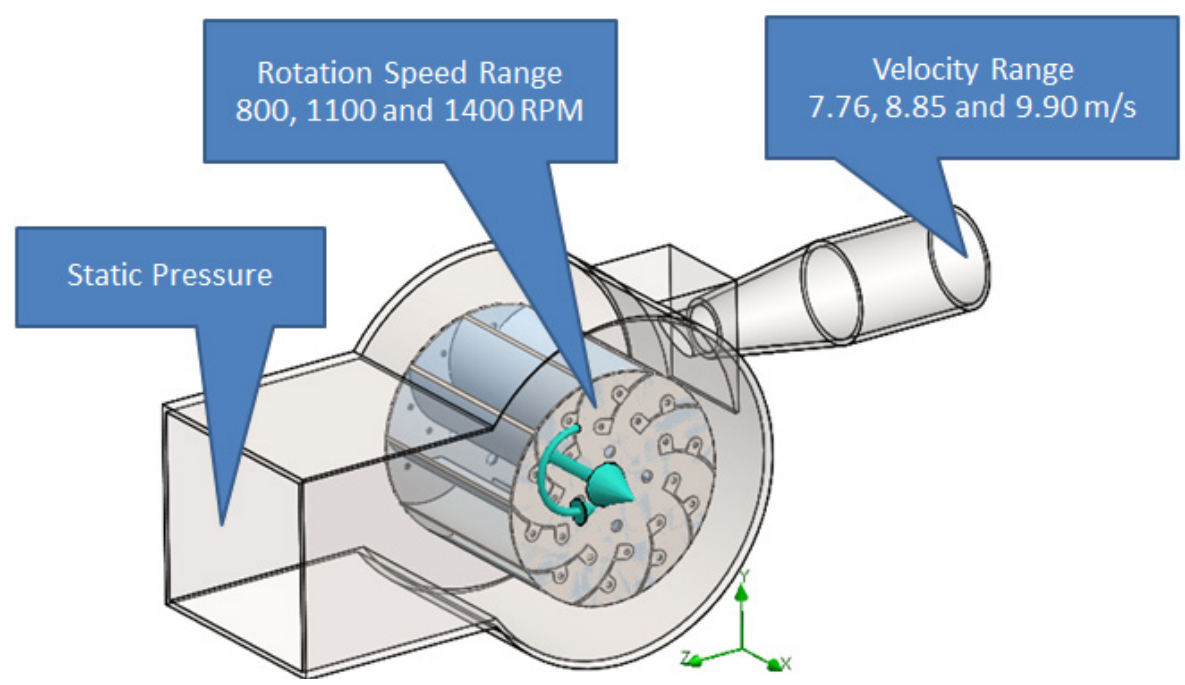

Figure 6 CFD boundary conditions for the micro water turbine.

Boundary conditions namely fixed support and applied a gravity load in the $\mathrm{Z}$ direction of the domain is $9.81 \mathrm{~m} / \mathrm{s}^{2}$ and the defined boundary conditions of the rotational speed setup were $800,1,100$, and 1,400 rpm as shown in Figure 7. Materials incorporated in the analysis are shown in Figure 8. 
http://wjst.wu.ac.th

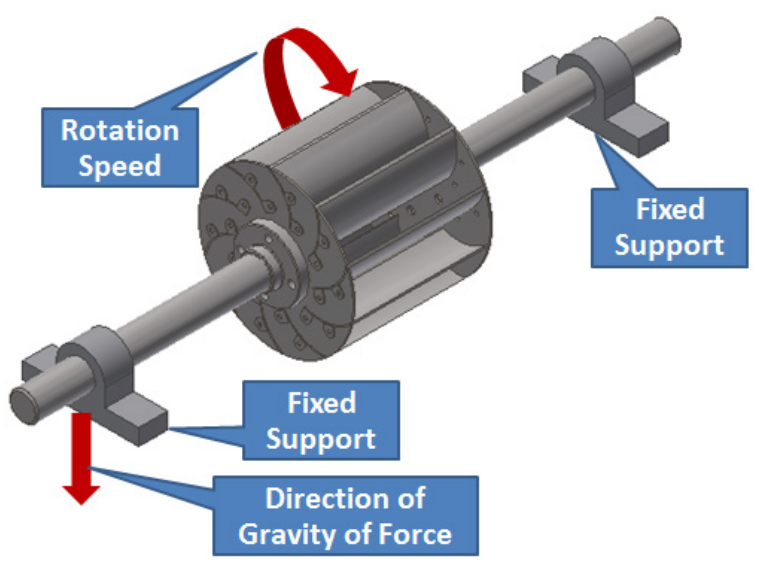

Figure 7 FEA boundary conditions for micro water turbine.

\begin{tabular}{|c|c|c|}
\hline \multicolumn{3}{|l|}{ V Basic Thermal } \\
\hline Thermal Conductivity & $1.670 \mathrm{E}+02 \mathrm{~W} /(\mathrm{m} \cdot \mathrm{K})$ & $\div$ \\
\hline Specific Heat & $0.897 \mathrm{~J} /\left(\mathrm{g} \cdot{ }^{\circ} \mathrm{C}\right)$ & $\div$ \\
\hline Thermal Exp...Coefficient & $23.600 \mu \mathrm{m} /\left(\mathrm{m} \cdot{ }^{\circ} \mathrm{C}\right)$ & $\div$ \\
\hline \multicolumn{3}{|l|}{ V Mechanical } \\
\hline Behavior & Isotropic & $r$ \\
\hline Young's Modulus & $68.900 \mathrm{GPa}$ & $\div$ \\
\hline Poisson's Ratio & 0.33 & $\because$ \\
\hline Shear Modulus & $25864.000 \mathrm{MPa}$ & $\div$ \\
\hline Density & $2.700 \mathrm{~g} / \mathrm{cm}^{3}$ & $\div$ \\
\hline \multicolumn{3}{|l|}{$\nabla$ Strength } \\
\hline Yield Strength & $275.000 \mathrm{MPa}$ & $\div$ \\
\hline Tensile Strenath & $310.000 \mathrm{MPa}$ & $\div$ \\
\hline
\end{tabular}

Figure 8 Material properties of the aluminum 6061 used in the wheel blade.

\section{Results and discussion}

CFD Simulation of the micro water turbine

The analysis and simulation were carried out using the Commercial software2018 program.

1) The following assumptions were incorporated for the CFD simulation:

- The type analysis is for internal flow

- The conditions are time-dependent and the flow is incompressible

2) Solution parameters for analysis $10^{-3}[10]$.

- The convergence criterion for continuity, velocity, and turbulence model parameters was set to 2.

- The defined micro wheel blade speeds under the water velocity conditions are shown in Table

3) Streamline and vector plots for the horizontal axis micro water turbine generator were created. 


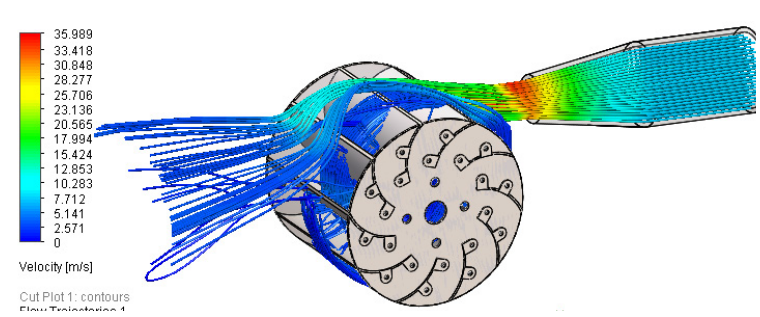

(a) Streamline plot.

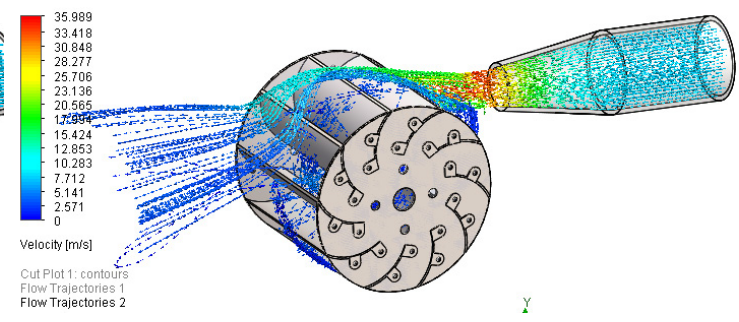

(b) Vector plot.

Figure 9 Streamline and Vector plot.

Figures 10a and 10b shown the velocity streamline and vectors plots in the wheel blade at inlet velocities of $7.76,8.85$, and $9.90 \mathrm{~m} / \mathrm{s}$, respectively. It can be seen that the velocity gradually increases from the mouth to the runner and then decreases, showing a loss of kinetic energy.

4) Velocity and pressure contours for different cases.

Case 1.1 Velocity and pressure distribution at $800 \mathrm{rpm}$.

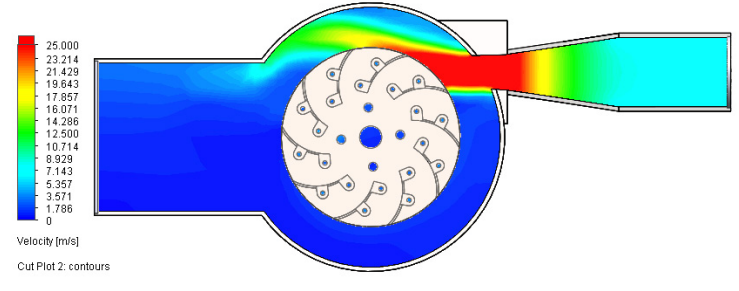

(a) Velocity.

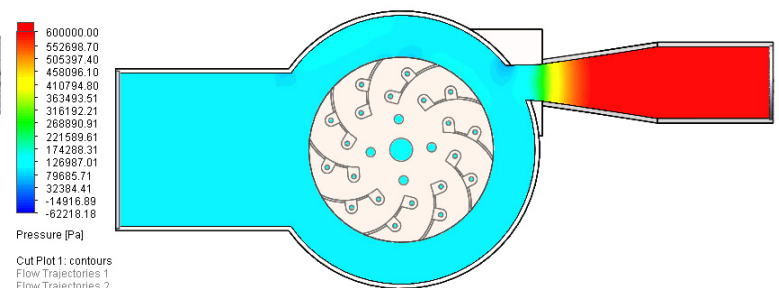

(b) Pressure.

Figure 10 Velocity and pressure distribution at $800 \mathrm{rpm}$.

Figure 10a shows the velocity contour of water inside the wheel blade and Figure 10b shows the pressure distribution contour at a maximum velocity of $7.76 \mathrm{~m} / \mathrm{s}$, with a wheel blade speed of $800 \mathrm{rpm}$.

Case 1.2 Velocity and pressure distribution at 1,100 rpm.

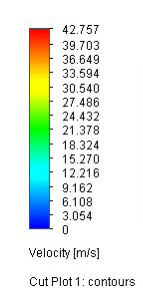

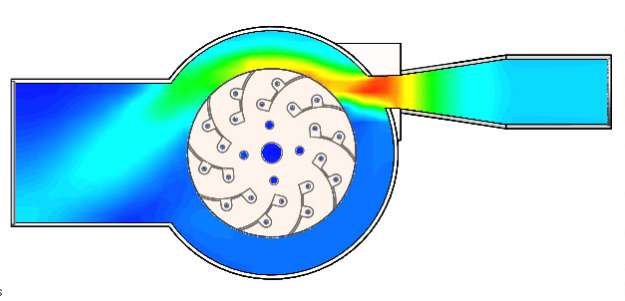

(a) Velocity.

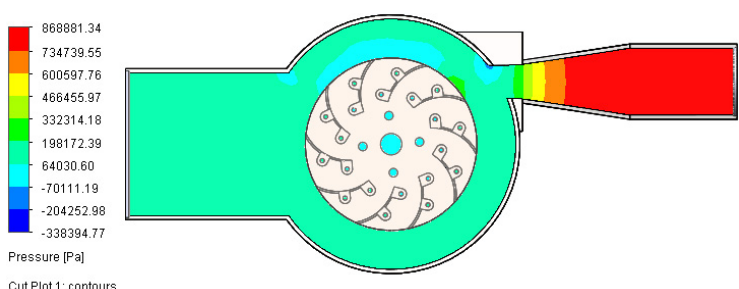

(b) Pressure.

Figure 11 Velocity and pressure distribution at 1,100 rpm. 
http://wjst.wu.ac.th

Figure 11a shows the velocity contour of water inside the wheel blade and Figure 11b shows the pressure distribution contour at a maximum velocity of $8.85 \mathrm{~m} / \mathrm{s}$, and a wheel blade speed of 1,100 rpm.

Case 1.3 Velocity and pressure distribution at 1,400 rpm

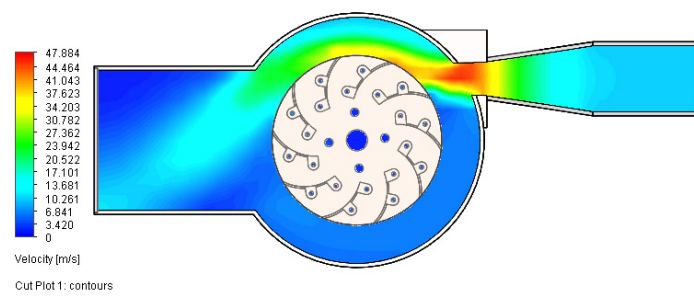

(a) Velocity.

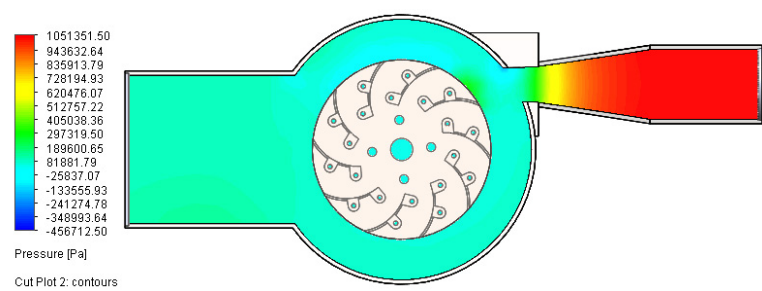

(b) Pressure.

Figure 12 Velocity and pressure distribution at 1,400 rpm.

Figure 12a shows the velocity contour of water inside the wheel blade and Figure 12b shows the pressure distribution contour at a maximum velocity of $9.90 \mathrm{~m} / \mathrm{s}$, and a wheel blade speed of 1,400 rpm.

Table 3 Power rate of the horizontal axis micro water turbine.

\begin{tabular}{ccc}
\hline Velocity speed $(\mathbf{m} / \mathbf{s})$ & Power transferred $(\mathbf{P t}) \mathbf{( W )}$ & KE Energy $(\mathbf{W})$ \\
\hline 7.76 & 36.61 & 41.34 \\
8.85 & 54.41 & 61.34 \\
9.90 & 76.29 & 85.87 \\
\hline
\end{tabular}

Table 4 Efficiency of the horizontal axis micro water turbine.

\begin{tabular}{ccc}
\hline Velocity speed $(\mathbf{m} / \mathbf{s})$ & Wheel blade speed (rpm) & Efficiency (\%) \\
\hline 7.76 & 800 & 88.55 \\
8.85 & 1,100 & 88.70 \\
9.90 & 1,400 & 88.84 \\
\hline
\end{tabular}

Results of the simulation are shown in Table 4. Which shows the efficiency value in relation to the velocity of water at different water head ranges. However, the efficiency value shown does not include a calculation for the loss rate in the water turbine system.

\section{Results of FEA}

The wheel blade is shown in Figures 2 and the meshing of the wheel blade is shown in Figure 6. The maximum von mises stresses at a rotation speed of $1,400 \mathrm{rpm}$ were calculated to be $0.2962 \mathrm{MPa}$ shown in Figure 13c. The total deformation when the water jet impacts on the blade were maximum at that point where water escapes from the blade after doing work. The maximum value of total deformation was $0.001189 \mathrm{~mm}$. 


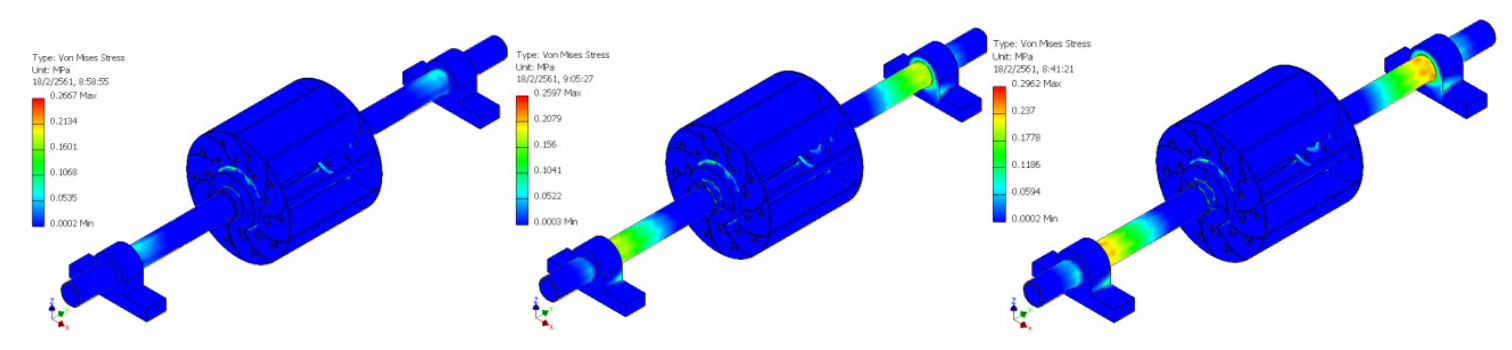
(a) $800 \mathrm{rpm}$.
(b) $1,100 \mathrm{rpm}$.
(c) $1,400 \mathrm{rpm}$.

Figure 13 The maximum von mises stresses.

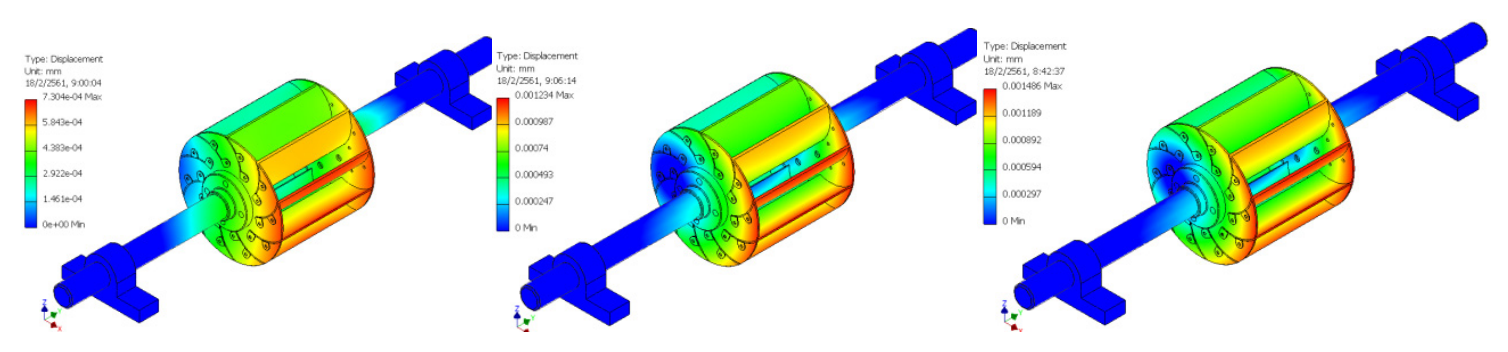
(a) $800 \mathrm{rpm}$.
(b) $1,100 \mathrm{rpm}$.
(c) $1,400 \mathrm{rpm}$.

Figure 14 The maximum value of total deformation.

Table 5 Maximum stresses and maximum displacement at various speeds for aluminum 6061.

\begin{tabular}{ccc}
\hline Speed (rpm) & Max. stress (Mpa) & Max. displacement (mm) \\
\hline 800 & 0.2667 & 0.000730 \\
1,100 & 0.2597 & 0.001234 \\
1,400 & 0.2962 & 0.001486 \\
\hline
\end{tabular}

Max. Displacement (mm.)

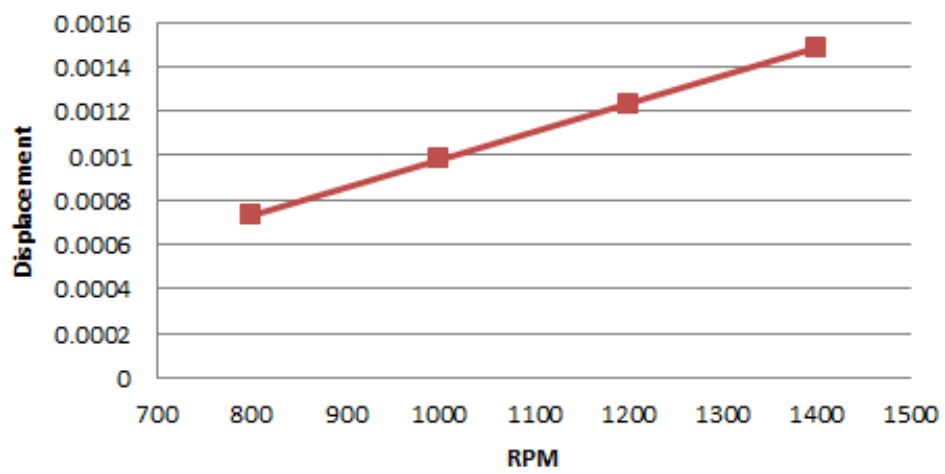

Figure 15 The relationship between the maximum displacement and rotation speed of the wheel blade. 
http://wjst.wu.ac.th

The relation between the maximum value of displacement and various speeds for Aluminum 6061 is shown in Figure 15. A clear linear response was determined.

Max. Stress (Mpa)

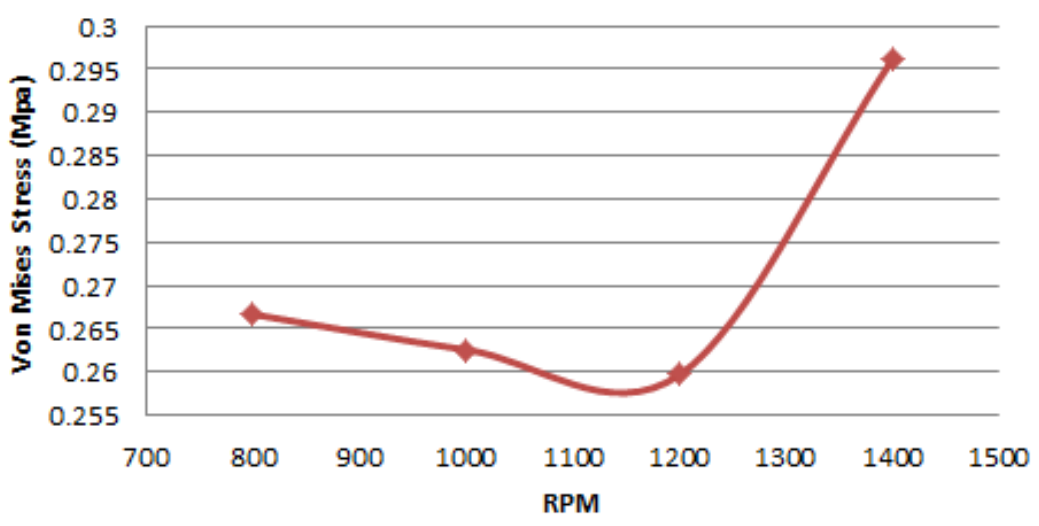

Figure 16 The relationship between the maximum stress and rotational speed of the wheel blade.

The relation between maximum value of stress distribution at various speeds for Aluminum 6061 is shown in Figure 16. Minimum values of stress occurred at a speed of 1,100 - 1,200 rpm.

\section{Discussion}

This is the $1^{\text {st }}$ report of the development of computational fluid dynamics and the result of finite element analysis for a horizontal axis micro water turbine. In this analysis, first of all, the simulation of CFD and FEA was carried out and then, for the purpose of validation, simulated results were compared with experimental results as per [14]. The key findings are as follows:

1. The maximum velocity of water was observed in the wheel blade section of the turbine.

2. The maximum pressure of water was observed in the wheel blade and volute sections.

3. The maximum deformation was observed in the wheel blade section and the minimum deformation occurred in the shaft and the bearings for the shaft.

4. Maximum stresses were observed in the wheel blade section at the shaft and bearing. The vonmises stresses were found to be within safe limits up to $1,400 \mathrm{rpm}$.

5. The stresses produced were within safe limits.

6. As the speed of the wheel blade was increased, the stress and displacement also increased.

After deriving the best model from the CFD analysis, FEA analysis was carried out on the wheel blade. The FEA analysis allowed the stresses and maximum values of total distribution deformation to be the calculation. Prediction of water turbine performance by FEA analysis, therefore, provides data on the loading of water velocity forces inside the water turbine model and gives information about the water force patterns that produce an optimum design for the development of a micro water turbine generator. We can employ such a type of horizontal axis micro water turbine to any open flow channels. We are going to discuss area where we can employ our turbine.

1. We can design these horizontal axes micro water turbines for streams where water moves with velocity and a relatively small head.

2. The modular design of a micro water turbine i.e., it can be assembled vertically, horizontally, or in any other crossflow combination using a common shaft and generator or an array of multiple turbines will find many applications in the commercial field. 
http://wjst.wu.ac.th

\section{Conclusions}

In this paper, it is tried to briefly introduce horizontal axis micro water turbine generator, In addition, we first studied the results of a real analysis based on theoretic and experimental fluid computation analyses, and then, we introduced the basics of designing and analysis of mechanical parts of the water turbine based on the general of water turbines designing after determining the general specifications of them. In several works of the literature on the case study for design low head type crossflow hydraulic turbine and case study of horizontal axis micro water turbine, it was indicated that attack angle should be kept as small as possible for maximum efficiency $[11,12]$. The stress analysis and fluid computation of 2 of the critical parts of this water turbine is also presented, which is an integrated part of mechanical analyses of these water turbines because of the fluctuation of the loads exerted to the horizontal axis micro water turbine generator. This result CFD and FEA simulation of can be calculated from the parameters mathematical from a design program for the development of a water volute and modeled of low head water turbine wheel for the community for high efficiency. From various design parameters; the best combination will give an efficient horizontal axis micro water turbine generator and successful implementation will help in eradicating power demands with some Installation cost and negligible maintenance, a lifelong clean source of energy in Thailand.

\section{Acknowledgements}

This research is financially supported by the lower north research network in Thailand of development and Rajamangala University of Technology Lanna Phitsanulok campus, Thailand.

\section{References}

[1] S Khurana, V Goel and A Kumar. FEM analysis of Turgo impulse turbine blade. Walailak J. Sci. Tech. 2013; 10, 363-8.

[2] Y Kyozuka. An experimental study on the Darrieus-Savonius turbine for tidal current power generation. J. Fluid Sci. Technol. 2008; 3, 439-49.

[3] NT Raj, PM Goud, PS Raman and R Mohan. Design, structural analysis of Pelton turbine bucket. Int. J. Adv. Res. Sci. Eng. 2017; 6, 454-60.

[4] M Maisuria and DA Patel. FE analysis of runner blade for small bulb turbine. IOSR J. Mech. Civ. Eng. 2014; 11, 73-7.

[5] A Sobachkin and G Dumnov. Numerical Basis of CAD-Embedded CFD. NAFEMS World Congress, 2013, p. 1-10.

[6] P Vaishaly and S Romarao. Finite element stress analysis of a typical stream turbine blade. Int. J. Sci. Res. 2015; 4, 1059-65.

[7] BR Cobb and KV Sharp. Impulse (Turgo and Pelton) turbine performance characteristics and their impact on pico-hydro installations. Renew. Energ. 2013; 50, 959-64.

[8] HP Neopane, OG Dhalhaug and B Thapa. Alternative design of a Francis turbine for sand laden water. In: Proceedings of the International Conference on Hydro-power-Hydro, Sri Lanka. 2007, p. $1-11$.

[9] W Lahamornchaiyakul. Application of K-epsilon and K-Omega turbulence model for rotation analysis of horizontal axis micro water turbine generator in community (in Thai). UBU Eng. J. 2018; 11, 95-104.

[10] Commercial softwareSoftware, Available at: http://solidapps.co.uk/blog/2016/08/use-of-solidworksflow-simulation-in-designing-a-suction-pump, accessed March 2017.

[11] M Girma and E Dribssa. Flow simulation and performance prediction of cross flow turbine using CFD tool. Int. J. Eng. Res. Gen. Sci. 2014; 2, 747-57.

[12] M Maisuria and DA Patel. FE analysis of runner blade for small bulb turbine. Modern Appl. Sci. 2014; 11, 73-7.

[13] W Lahamornchaiyakul. 2018, Mechanical Part for Aerator in Water, Thailand Patent 62881. 
http://wjst.wu.ac.th

[14] P Gunai, S Gumaste, S Gathe and AK Das. Design, analysis and improvisation of helical cross flow hydro kinetic turbine. Int. J. Adv. Eng. Res. Sci. 2016; 3, 36-41. 